\title{
CD226 knockout alleviates high-fat diet induced obesity by suppressing proinflammatory macrophage phenotype
}

\author{
Jingchang $\mathrm{Ma}^{1 \dagger}$, Wei Hu${ }^{1 \dagger}$, Dongliang Zhang ${ }^{1}$, Jiangang Xie', Chujun Duan ${ }^{1}$, Yitian Liu' ${ }^{1}$, Yuling Wang ${ }^{1}$,
} Xuexue $\mathrm{Xu}^{2}$, Kun Cheng ${ }^{1}$, Boquan Jin ${ }^{1}$, Yuan Zhang ${ }^{2^{*}}$ and Ran Zhuang ${ }^{1,2^{*}}$ (D)

\begin{abstract}
Obesity is associated with chronic low-grade inflammation, contributing to an increasing prevalence of chronic metabolic diseases, such as insulin resistance, non-alcoholic fatty liver disease (NALFD), and steatohepatitis. Macrophages are the predominant immune cells in adipose tissues. Adipose tissue macrophages (ATMs) would switch to pro-inflammatory M1 state during obesity, causing local and systemic inflammation. However, the regulatory mechanism of ATMs has not yet been well described within this process. Using a high-fat diet (HFD)-induced mouse obesity model, we found that the costimulatory molecule CD226 was highly expressed on ATMs and knockout (KO) of CD226 alleviated obesity caused by HFD. Loss of CD226 reduced the accumulation of ATMs and hindered macrophage M1 polarization, with lower serum proinflammatory cytokine levels. Furthermore, deficiency of CD226 on ATMs decreased the phosphorylation levels of VAV1, AKT, and FOXO1 and thereby upregulated PPAR-ץ. Further administration of PPAR- $\gamma$ inhibitor restored M1 phenotype in CD226KO ATMs. In summary, loss of CD226 alleviates the HFD-induced obesity and systemic inflammation through inhibition of the accumulation and M1 polarization of ATMs in which PPAR- $\gamma$-dependent signaling pathway is involved, suggesting that CD226 may be identified as a potential molecular target for the clinical treatment of obesity.
\end{abstract}

Keywords: CD226, HFD, Obesity, Macrophage, Polarization

\section{Introduction}

Obesity is a chronic systemic inflammatory disorder characterized by the dysfunction of hypertrophied adipocytes and the accumulation of immune cells in adipose tissue [1]. The development of inflammation within adipose tissue contributes to proinflammatory status and metabolic dysfunction in the whole body, including type II diabetes mellitus, non-alcoholic fatty liver disease

\footnotetext{
*Correspondence: zhangyuan_nwpu@nwpu.edu.cn; fmmuzhr@fmmu.edu.cn †Jingchang Ma and Wei Hu are contributed equally to this work ${ }^{1}$ Department of Immunology, Fourth Military Medical University, 169 West Changle Road, Xi'an 710032, Shaanxi, China

${ }^{2}$ Institute of Medical Research, Northwestern Polytechnical University,

127 West Youyi Road, Xi'an 710072, Shaanxi, China
}

(NALFD), atherosclerosis, and ischemic cardiovascular disease [2].

Macrophages are the predominant immune cells in adipose tissue, and they accumulate in obese mice and humans [2, 3]. Macrophages are heterogeneous. They are classified to be classically (M1) or alternatively (M2) activated based on distinct patterns of gene expression and function [4]. It has been proposed that during obesity, macrophages in adipose tissue (ATMs) undergo a 'phenotypic switch' from an anti-inflammatory M2 phenotype to a pro-inflammatory M1 state, and this conversion was a key contributor to the emergence of the local and systemic inflammation of adipose tissues [5]. However, the molecular details underlying inflammatory responses original author(s) and the source, provide a link to the Creative Commons licence, and indicate if changes were made. The images or other third party material in this article are included in the article's Creative Commons licence, unless indicated otherwise in a credit line to the material. If material is not included in the article's Creative Commons licence and your intended use is not permitted by statutory regulation or exceeds the permitted use, you will need to obtain permission directly from the copyright holder. To view a copy of this licence, visit http://creativecommons.org/licenses/by/4.0/. The Creative Commons Public Domain Dedication waiver (http://creativeco mmons.org/publicdomain/zero/1.0/) applies to the data made available in this article, unless otherwise stated in a credit line to the data. 
and the regulatory mechanism of ATMs in obese adipose tissue remain uncertain.

CD226-also known as DNAX accessory molecule 1is an important costimulatory receptor on $\mathrm{T}$ cells, NK cells, and monocytes/macrophages [6-9]. Previous studies regarding CD226 primarily focused on its regulation on the $\mathrm{T}$ and NK cells, while recently emerging reports believe that CD226 is also involved in the processes of macrophage polarization, migration, and other functions. It was studied that CD226 deletion improved post-infarction healing and cardiac function by favoring macrophage polarization towards reparative phenotype [10]. CD226 also played a costimulatory role in antigen presentation by small peritoneal macrophages [11]. However, since macrophages are highly heterogeneous in various tissue content, the regulation of CD226 on ATMs needs to be studied, especially considering that macrophages are the most abundant immune cells in adipose tissues. In the present study, we utilized CD226 knockout (KO) mice to observe the roles of CD226 deficiency in the obesity and its related systemic inflammation induced by a high-fat diet (HFD). We found that deficiency of CD226 alleviated obesity and inflammatory state via inhibition of the ATM accumulation and the proinflammatory phenotype of macrophages. The potential underlying mechanism involved in this regulation was the peroxisome proliferator-activated receptor gamma (PPAR- $\gamma$ )dependent signaling pathway.

\section{Materials and methods \\ Clinical serum}

For the detection of soluble CD226 in serum, 79 samples were randomly selected from the clinical laboratory of Tangdu Hospital of Fourth Military Medical University (48 females and 31 males). Additional file 6: Table S1 showed the basic detailed information for participants. Subjects with inflammatory disorders, metabolic related diseases, or anti-inflammatory drug use were excluded. According to the Chinese standard of body mass index (BMI), we divided the subjects into three groups: normal group (BMI: 18.5-23.9; 35 samples), overweight group (BMI: 24.0-27.9; 31 samples) and obese group (BMI: $\geq 28.0 ; 13$ samples). All procedures were approved by the Tangdu Hospital ethics committee and conformed with the principles of Helsinki Declaration, and all participants provided written and/or oral informed consent. The sera were stored at $-20^{\circ} \mathrm{C}$ until use.

\section{Mice}

CD226KO mice on a C57BL/6 background were kindly provided by Professor Marco Colonna [12]. CD226KO mice were hybridized with C57BL/6 wildtype (WT) mice (the Animal Center of the Fourth Military Medical
University, Shaanxi, China) for several generations. Homozygous CD226 KO mice and their WT littermates were then used for following experiments. The WT and CD226KO mice were fed with a standard chow that provided $10 \%$ of calories from fat and a HFD consisting of $60 \%$ fat for 16 weeks, respectively, beginning at the age of 5-6 weeks. We used inter-cage rotation procedure to mitigate the potential cage effects on the intestinal microbiota $[13,14]$. All experiments using mice were performed according to the Guide for the Care and Use of Laboratory Animals (NIH, Bethesda, MD) and approved by the Institutional Animal Care and Use Committee of the Fourth Military Medical University.

\section{Materials}

FCS antibodies, APC-CD226 (clone: 10E5, No: 17-226182) and PE-F4/80 (clone: BM8, No: 12-4801-82), PECy5CD11c (clone: N418, No: 15-0114-81), FITC-F4/80 (clone: BM8, No: 11-4801-82), Fixable Viability Dye eFluor $^{\mathrm{TM}} 506$ (No: 65-0866-14) and MitoSOX ${ }^{\mathrm{TM}}$ Red mitochondrial superoxide indicator (No: M36008) were supplied by Thermo Fisher Scientific Inc. (Waltham, MA, USA). FCS antibodies, FITC-CD11c (clone: N418, No: 117306), AF700-CD45 (clone: 30-F11, No: 103128), FITC-CD226 (clone: 10E5, No: 128803), PE-CD226 (clone: 10E5, No: 128806), APC-CD155 (clone: TX56, No: 131510), and APC-F4/80 (clone: BM8, No: 123116) were purchased from BioLegend (San Diego, CA, USA). The chow ( $10 \%$ of calories derived from fat, No: MD12031) and food for the HFD groups (60\% of calories derived from fat, No: MD12032) were purchased from Medicience Ltd. (Yangzhou, Jiangsu, China). The triglyceride assay kit (No: C061), low-density lipoprotein cholesterol (LDL-C) assay kit (No: C063), highdensity lipoprotein cholesterol (HDL-C) assay kit (No: C063), total cholesterol assay kit (No: C063), alanine aminotransferase (ALT) assay kit (No: C052), aspartate aminotransferase (AST) assay kit (No: C072), gammaglutamyltransferase ( $\gamma$-GT) assay kit (No: C009), alkaline phosphatase (ALP) assay kit (No: C003), and glycosylated serum protein assay kit (No: C024) were purchased from Changchun Huili Biotech Co., Ltd. (Changchun, Liaoning, China). The following antibodies were used for western blotting and immunofluorescence: anti-PPAR- $\gamma$ mAb (clone: C26H12, No: 2435), anti-AKT mAb (clone: 40D4, No: 2920), anti-p-AKT Ser473 mAb (clone: D9E, No: 4060), anti-p-FOXO1 Ser256 mAb (clone: E1F7T, No: 84192), and anti-perilipin-1 mAb (clone: D1D8, No: 9349), purchased from Cell Signaling Technology (Danvers, MA, USA); anti-p-VAV1 Tyr174 mAb (clone: 28.Tyr 174, No: sc-135785), anti-VAV1 mAb (clone: D-7, No: sc-8039), anti-FOXO1 mAb (clone: C-9, No: sc-374427), and anti- $\beta$-ACTIN mAb (clone: 2Q1055, No: sc-58673), 
purchased from Santa Cruz Biotechnology Inc. (Dallas, TX, USA); anti-F4/80 mAb (clone: CI:A3-1, No: ab6640), purchased from Abcam Inc. (Cambridge, Cambridgeshire, UK); and CD226 pAb (No: 50232-M08H), purchased from Sino Biological Inc. (Beijing, China). Functional grade CD226 monoclonal antibody (clone: 10E5) was provided by Thermo Fisher Scientific Inc. The PPAR- $\gamma$ selective inhibitor GW9662 (No: S2915) was supplied by Selleck Chemicals (Houston, TX, USA). The secondary immunofluorescence antibodies used were as follows: CY3-goat anti-rabbit antibody (No: BA1032), supplied by Boster Biological Technology Co., Ltd. (Wuhan, Hubei, China); and Alexa Fluor 488-goat anti-rabbit antibody (No: GB25303) and CY3-goat anti-rat antibody (No: GB21302), supplied by Wuhan Servicebio Technology Co., Ltd. (Wuhan, Hubei, China). Collagen type I (No: DY40127) was purchased from Diyi Biotechnology Inc. (Shanghai, China), and lipopolysaccharide (LPS) (No: L2630) was purchased from Sigma-Aldrich Inc. (St. Louis, MS, USA).

\section{Sandwich ELISA}

The anti-human CD226 monoclonal antibodies (mAbs) and ELISA kit were used as previously described [15]. Briefly, $100 \mu \mathrm{l}$ of anti-human CD226 mAb $(10 \mu \mathrm{g} / \mathrm{ml}$ in $0.05 \mathrm{M}$ sodium carbonate buffer, $\mathrm{pH}$ 9.5) was added to each well of a Nunc Maxisorp ELISA plate (Nunc, Rochester, NY, USA) and incubated overnight at $4{ }^{\circ} \mathrm{C}$. After a $3 \times$ wash, plasma samples or standard CD226 recombinant protein serially diluted with PBS containing $0.1 \%$ BSA and $0.1 \%$ Tween- 20 were added to the wells and incubated for $1 \mathrm{~h}$ at $37^{\circ} \mathrm{C}$. After extensive washing with PBS containing $0.1 \%$ Tween-20 (PBST), the wells were incubated with another anti-human CD226 mAb conjugated with biotin for $1 \mathrm{~h}$ at $37^{\circ} \mathrm{C}$. Then, $100 \mu \mathrm{l}$ of commercial streptavidin-horseradish peroxidase (HRP) was added and color development was performed on a TMB visualized system. $450 \mathrm{~nm}$ absorbance was determined with a microplate reader (Bio-Rad, CA, USA).

\section{Histology}

After feeding a HFD for 16 weeks as indicated, epididymal adipose tissues and livers were harvested from mice and dissected. The tissues were fixed in $4 \%$ buffered formalin overnight, then embedded in paraffin and cut into sections $4 \mu \mathrm{m}$ in thickness. Following standard procedures, the sections were stained with Hematoxylin and eosin (H\&E) to determine morphological changes according to our previous study [16]. For Oil Red O (ORO) staining, the tissues were embedded in OCT medium after fixing in $4 \%$ buffered formalin overnight. Then, the tissues were cut into Sects. $10 \mu \mathrm{m}$ in thickness.
ORO staining was performed according to a previous study [17].

\section{Flow cytometry}

Epididymal fat tissues and spleens were harvested from mice after 16 weeks of HFD. After shearing with ophthalmic scissors, the epididymal fat was collected in a centrifuge tube and digested with collagen type I at $37{ }^{\circ} \mathrm{C}$ for $15 \mathrm{~min}$. Triple fetal bovine serum (FBS)-containing medium was used for neutralization. The cell suspension was passed through a $40 \mu \mathrm{m}$ cell strainer. The stromal vascular fraction (SVF) of the epididymal fat was obtained after centrifuging. Splenocytes were treated with $\mathrm{NH}_{4} \mathrm{Cl}$ buffer for $5 \mathrm{~min}$ to lyse the red blood cells. Flow cytometry staining was performed according to our previous study [16]. Briefly, prior to surface staining with antibodies, Fc-gamma receptors were blocked by incubating cells with anti-CD16/CD32 antibodies (eBioscience, 14-0161-82). Thereafter, cells were incubated with the appropriate primary antibodies diluted in FACS buffer (DPBS + 2\% FCS) for $30 \mathrm{~min}$ at $4{ }^{\circ} \mathrm{C}$. Cells were analyzed with a NovoCyte flow cytometer (ACEA Bioscience). Data were analyzed using NovoExpress software (ACEA Bioscience).

\section{Immunofluorescence}

Epididymal adipose tissue was obtained from mice fed with a HFD or chow at 16 weeks as indicated. The tissues were first fixed with $4 \%$ buffered formalin overnight, and then embedded in paraffin and cut into 4- $\mu$ m thick sections. Following standard deparaffinization procedures as described previously [18], these sections were blocked with $3 \%$ BSA plus $0.1 \%$ Triton-X100 for $30 \mathrm{~min}$ at room temperature, then incubated with primary antibodies, anti-mouse F4/80, anti-mouse CD226, and anti-mouse perilipin-1 for $1 \mathrm{~h}$ at room temperature, and finally stained with the corresponding immunofluorescence secondary antibodies and DAPI. Images were obtained using a confocal microscope (LSM 800, Zeiss, Germany).

\section{Metabolic phenotype assays}

To analyze the glycolytic rate or metabolic phenotype, the real-time extracellular acidification rate of CD226KO and WT ATMs was recorded by an XFp analyzer provided by Agilent Technologies Inc. (Paloalto, CA, USA). ATMs were seeded into an XFp cell culture plate at a density of $3 \times 10^{4}$ cells/well in $80 \mu \mathrm{L}$ RPMI1640 medium (containing 10\% FBS and 1\% penicillin-streptomycin). Following adhesion for $24 \mathrm{~h}$, the medium was replaced with $180 \mu \mathrm{L}$ correspondingly Seahorse-DMEM medium (containing $0.5 \% \mathrm{BSA}$ and $2 \mathrm{mM}$ glutamine). After machine testing, $10 \mathrm{mM}$ glucose, $1 \mu \mathrm{M}$ oligomycin, and 
$50 \mathrm{mM}$ 2-deoxy-glucose were sequentially added to the media for analysis and recording.

\section{Dual-luciferase reporter assay}

RAW264.7 cells were seeded in a 24-well plate in RPMI1640 medium containing 10\% FBS without penicillin-streptomycin for adhesion. Then, the medium was changed to Opti-MEM, and the cells were starved for $1 \mathrm{~h}$. According to the manufacturer's instructions, RAW264.7 cells were transfected with pGL3-PPAR- $\gamma$ promoter or pGL3-basic plasmids by Lipofectamine 3000. pGL3-basic plasmids and pGL3-PPAR- $\gamma$ promoter, which contain firefly and Renilla luciferase genes, were constructed by TsingKe. (Beijing, China). After an additional $24 \mathrm{~h}, 5 \mu \mathrm{g} /$ $\mathrm{ml} 10 \mathrm{E} 5$ functional antibody (incubated and bound on protein $\mathrm{G}$ beads) or isotype antibody was added to stimulate the transfected RAW264.7 cells for another $24 \mathrm{~h}$. The cells were first lysed using cell lysis solution provided by Beyotime Biotechnology Inc. (Shanghai, China). Firefly fluorescein enzyme and Renilla luciferase activity were then sequentially measured according to the manufacturer's instructions. Normalization of the relative light unit of firefly fluorescein to that of Renilla fluorescein was conducted to control for cell number and protein content variation. Finally, the relative light unit ratio was calculated.

\section{Immunoblot analysis}

The cells were collected and lysed with RIPA buffer containing $1 \mathrm{mM}$ phenylmethylsulfonyl fluoride and protease and phosphatase inhibitors (Roche Applied Science). Lysates were centrifuged at $10,000 \mathrm{~g}$ for $10 \mathrm{~min}$ at $4{ }^{\circ} \mathrm{C}$. The supernatant was collected and its protein concentration was measured using the DC protein assay kit (5000116, Bio-rad). First, $50 \mu \mathrm{g}$ of total protein was loaded in each well of the gradient gel. Second, proteins were transferred onto a PVDF membrane (Bio-rad, 1704156) with a semidry system and subsequently blocked for $1 \mathrm{~h}$ at room temperature with $5 \%$ milk in $0.1 \%$ TBSTween. Third, the membranes were incubated overnight at $4{ }^{\circ} \mathrm{C}$ with primary antibodies. The appropriate HRPlinked secondary antibodies were used for chemiluminescent detection of proteins. Final, the membranes were scanned with a Chemidoc imaging system (Bio-rad) and quantified using Image Lab 6 software (Bio-rad).

\section{Cell culture}

The SVF was isolated from the epididymal fat tissue using sterile collagen type I and then cultured in RPMI1640 medium containing $10 \%$ FBS and $1 \%$ penicillin-streptomycin. Following adhesion for $24 \mathrm{~h}$, the supernatant was removed and discarded, then the ATMs were obtained. Peritoneal macrophages were isolated using PBS. Briefly, mice were euthanized with isoflurane, then precooled PBS was injected intraperitoneally and used to lavage the peritoneal macrophages. After seeding in a 24-well plate, the peritoneal macrophages were purified by discarding the suspended cells. Finally, the purified peritoneal macrophages were stimulated with or without $100 \mathrm{ng} / \mathrm{ml}$ LPS for $12 \mathrm{~h}$, and quantitative real-time PCR (qPCR) was further performed to measure the expression levels of target genes. For the PPAR- $\gamma$ blocking experiment, RAW264.7 cells were pre-treated with or without GW9662 $(10 \mu \mathrm{M})$ for $24 \mathrm{~h}$, then incubated with $100 \mathrm{ng} / \mathrm{mL}$ LPS for $12 \mathrm{~h}$. Finally, flow cytometry analysis and qPCR were performed to examine the polarization of macrophages.

\section{Quantitative real-time PCR}

Total RNA from the aforementioned tissues and cells was isolated with TRIzol Reagent (Invitrogen, Carlsbad, CA, USA). Then, $1 \mu \mathrm{g}$ total RNA was reverse transcribed into cDNA by PrimeScript ${ }^{\mathrm{TM}}$ II 1st Strand cDNA Synthesis (TaKaRa, Dalian, Liaoning, China). Finally, qPCR was performed using SYBR Green as the detection system (TaKaRa) in a CFX96 Real-Time PCR System (Bio-Rad, Hercules, CA, USA). The sequences of the qPCR primers used are summarized in Additional file 6: Table S2.

\section{Statistics}

Results were presented as mean \pm standard error (SEM). A two-tailed, unpaired Student's $t$-test (for comparison within two groups) or Kruskal-Wallis test with Dunn's multiple test (for score related or clinical data comparison) or one way ANOVA with Tukey's multiple test (for comparison within three or more groups) was performed using GraphPad Prism software (San Diego, CA, USA). A $P$-value less than 0.05 was considered statistically significant $\left({ }^{*} P<0.05,{ }^{* *} P<0.01\right)$. Three independent experiments were performed and each contained 3 replicates.

\section{Results}

\section{HFD increases CD226 expression on ATMs}

We examined the serum concentration of soluble CD226 in 79 human clinical samples (Normal 35, Overweight 31, Obesity 13), and found that the concentration of serum CD226 was significantly higher in the obesity cohort (median: $7.47 \mathrm{ng} / \mathrm{ml}$, interquartile range [IQR]: $5.33-9.60 \mathrm{ng} / \mathrm{ml}$ ) compared with the both normal (median: $3.96 \mathrm{ng} / \mathrm{ml}$, IQR: $1.76-6.69 \mathrm{ng} / \mathrm{ml}$ ) and overweight (median: $4.90 \mathrm{ng} / \mathrm{ml}$, IQR: $3.10-6.75 \mathrm{ng} / \mathrm{ml}$ ) groups (Fig. 1A), suggesting that CD226 might be related to the occurrence of obesity. Besides, the expression profiles of CD226 on myeloid cells (including monocytes, macrophages, and neutrophils) from immunological consortium ImmGen (Immunological Genome Project) [19] 
showed that CD226 expression on ATMs was higher than that on others (Fig. 1B).

Tissue macrophages are phenotypically heterogeneous. Through an obese mouse model, although the expression of $\mathrm{CD} 226$ was comparable between $\mathrm{F} 4 / 80^{+}$splenic macrophages from HFD-fed mice and those from chowfed mice, its expression on F4/80 ${ }^{+}$ATMs from epididymal SVF of HFD-fed mice was significantly higher than that of chow-fed mice (Fig. 1C, D). Epididymal fat and SVF samples of HFD-fed mice also showed significantly increased $C d 226$ mRNA levels than chow-fed mice (Additional file 1: Fig. S1A). However, HFD did not much alter the expression levels of $\mathrm{CD} 226$ on $\mathrm{CD} 4^{+}, \mathrm{CD} 8^{+}$, and NK cells in epididymal adipose tissues (Additional file 1: Fig. S1B). We further detected the expression of CD155 (a ligand of CD226) in ATMs derived from HFDfed mice, which was also significantly higher (Additional file 1: Fig. S1C). Immunofluorescence staining of epididymal fat tissues showed crown-like structures of ATMs in HFD-fed mice, with CD226 robustly expressing on these crown-like structures (Fig. 1E). Moreover, CD226 was also upregulated in liver $\mathrm{F} 4 / 80^{+}$cells from HFD-fed mice and in RAW264.7 cells following LPS stimulation (Additional file 1: Fig. S1D, S1E). These data indicate a potential role of CD226 in ATMs of HFD-induced obese mice.

\section{CD226KO ameliorates HFD-induced obesity}

To determine whether CD226 is involved in the occurrence of HFD-induced obesity, we examined the metabolic phenotype of CD226KO mice. Genotype identification of CD226KO mice was performed before the experiments (Additional file 2: Fig. S2A). After HFD feeding, the increased weight of obese mice in the $\mathrm{KO}$ group was significantly lower than that of WT mice (Fig. 2A, B). $H \& E$ staining and immunofluorescence staining of perilipin-1 indicated a suppressed increase of adipocyte size in the HFD CD226KO group compared with the HFD WT group (Fig. 2C, D). Additionally, the compensatory hyperplasia of islet tissue was significantly decreased in the HFD CD226KO group (Fig. 2E, F). The HFD-induced increases of serum levels of triglyceride, HDL-C, LDL-C, and total cholesterol were also relieved by CD226 deficiency (Fig. 2G).

Recent research has established that obesity is associated with chronic low-grade inflammations, contributing to an increasing prevalence of chronic metabolic diseases, such as NALFD and steatohepatitis [2]. Here, we found that the liver function parameters, including AST, ALT, $\gamma$-GT, and ALP, were decreased in the HFD CD226KO mice compared with the HFD WT group (Additional file 3: Fig. S3A). The increase of liver size and weight in HFD-fed CD226KO mice was significantly reduced compared with HFD-fed WT controls (Additional file 3: Fig. S3B, S3C). Clusters of lipid droplets detected by ORO staining were reduced in HFD CD226KO mice compared with the HFD WT group (Additional file 3: Fig. S3D). Meanwhile, H\&E images of liver tissues showed that the HFD-caused pathological damages including steatosis and ballooning were also attenuated in CD226KO mice (Additional file 3: Fig. S3E). These data demonstrate that CD226KO mice are protected from HFD-induced obesity and its related liver damage.

\section{CD226KO suppresses ATM accumulation in mice after HFD} In obese patients and mice, accumulation of ATMs, especially inflammatory ATMs, is significantly increased, contributing to the inflammation of adipose tissues [20, 21]. We detected the accumulation and inflammatory phenotype of ATMs in visceral fat. In the spleen, the percentages of $\mathrm{F} 4 / 80+$ macrophages were increased in the HFD-fed mice compared with chowfed group, but CD226KO did not alter the macrophage amount (Fig. 3A). However, HFD led to markedly increased macrophages in epididymal SVF samples, which was significantly alleviated by further CD226KO (Fig. 3B). Nevertheless, following CD226KO had no significant effect on the proportion of $\mathrm{CD} 4^{+}, \mathrm{CD}^{+}$and NK cells in white adipose tissues after HFD (Additional file 4: Fig. S4A). Using immunofluorescence staining, crown-like structures could be observed in epididymal adipose tissue sections from HFD-fed mice. In HFD-fed CD226KO mice, F4/80 ${ }^{+}$cells and the crownlike structures were reduced (Fig. 3C). The absolute counts of isolated SVF cells and F4/80 + ATMs in the HFD CD226KO group were also lower than HFD WT (Fig. 3D). These results suggest that CD226 is required for obesity-induced ATM accumulation.

\footnotetext{
(See figure on next page.)

Fig. 1 HFD increased CD226 expression in ATMs. A Comparison of soluble CD226 levels in sera of normal, overweight and obese individuals. Plots show individual data values obtained (79 individuals in total). Horizontal black lines represent median \pm IQR. Differences between groups were determined by Kruskal-Wallis test. B The expression profiles of CD226 on myeloid cells, including monocytes, macrophages, and neutrophils. C, D FACS analysis of CD226 expression on macrophages in the spleen and epididymal SVF of C57BL mice fed with chow or a HFD for 16 weeks $(n=3)$. E Immunofluorescence staining for F4/80 (red) and CD226 (green) in the epididymal fat of mice fed with chow or a HFD for 16 weeks ( $n=3$ ). Scale bar means $100 \mu \mathrm{m}$. Data represent mean \pm SEM. Differences between groups were determined by two-tailed, unpaired Student's $t$-test. ${ }^{*} P<0.05$, ${ }^{*} P<0.01$
} 
A

B
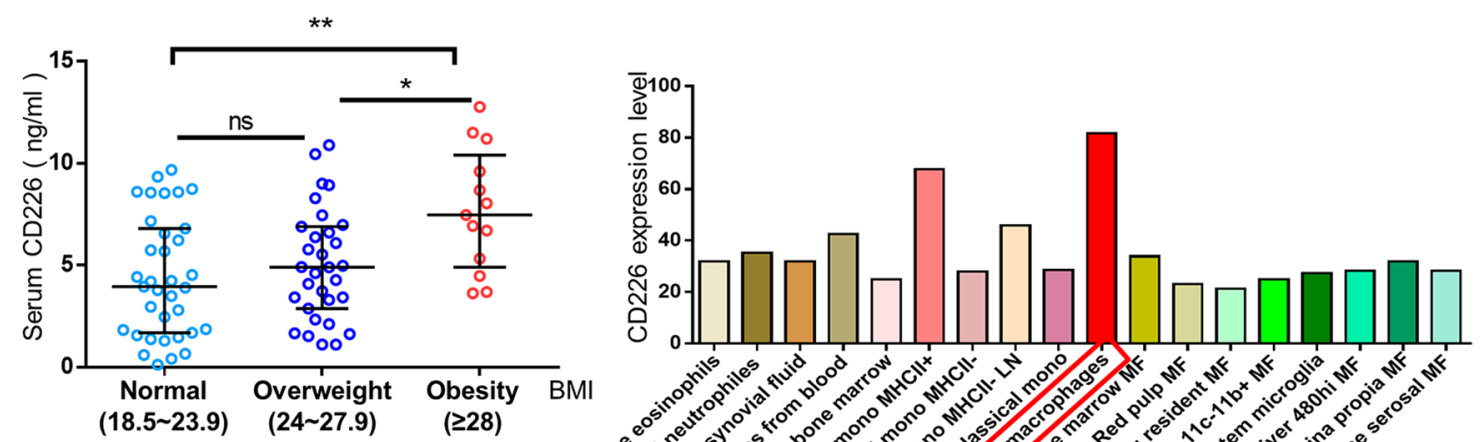

C

Spleen
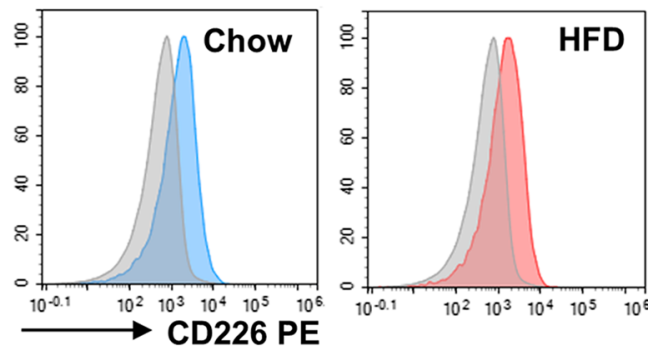

D SVF

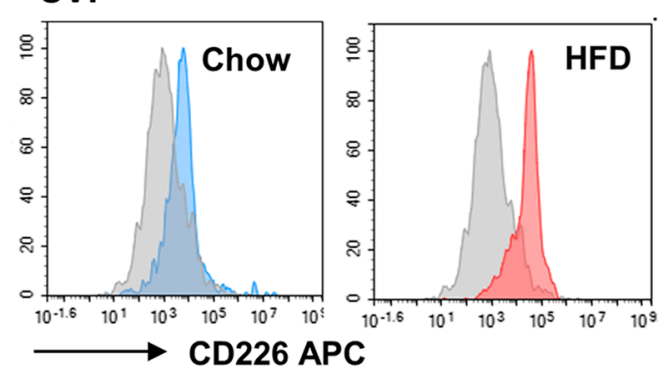

E

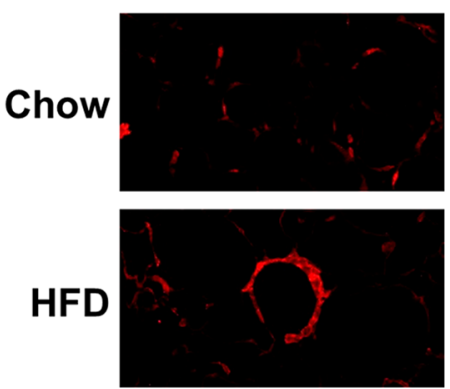

$\mathrm{F} 4 / 80$
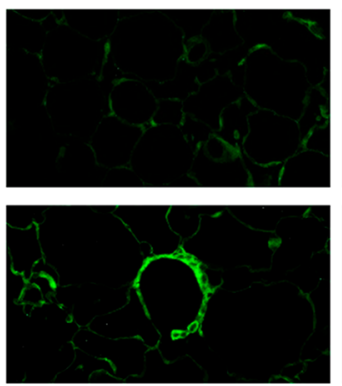

CD226
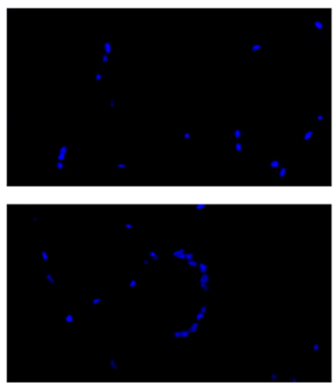

DAPI
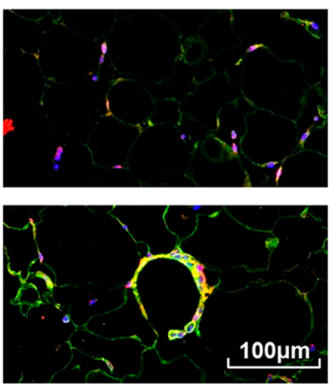

Merge

Fig. 1 (See legend on previous page.) 


\section{CD226KO inhibits the M1 proinflammation phenotype of ATMs after HFD}

Given that CD226 deficiency improved obesity and its related systemic inflammation, we investigated the inflammatory phenotype of the accumulated ATMs. Luminex analysis showed that in the HFD-induced obesity mouse model, there was an obvious increase in serum proinflammation cytokines such as TNF- $\alpha$, MCP1, IL-12, IL-1 $\beta$, IL-6, CCL3, CXCL16, and Resistin, which were further alleviated significantly in the CD226KO group (Fig. 4A). Furthermore, the $\mathrm{CD} 11 \mathrm{c}^{+}$percentage in epididymal ATMs (M1-type) decreased in HFDfed CD226KO mice compared with the HFD-fed WT (Fig. 4B). We then isolated and cultured ATMs from the epididymal adipose tissue of HFD-fed mice for ex vivo experiments and analyzed the culture supernatant. The ATMs derived from CD226KO mice produced fewer proinflammatory cytokines than those from WT mice, both at the protein level as detected by Luminex analysis (Additional file 5: Fig. S5A) and at the mRNA level as detected by qPCR (Fig. 4C). These results showed that M1 markers or proinflammatory cytokines in the SVF of HFD-fed obese mice were lower in the CD226KO group, whereas M2 markers were higher, indicating that the proinflammatory ATM state and M1 polarization were suppressed in obese CD226KO mice.

Diverse traits characterize the phenotypes and bioenergetics of macrophages in different states. It is accepted that inflammatory M1 macrophages are more likely to depend on aerobic glycolysis to support their functions. Reportedly, aerobic glycolysis was significantly increased in SVF and ATMs isolated from obese mice compared with those isolated from lean mice [5]. In the present study, functional metabolic analysis was performed to assess the glycolysis rates of epididymal ATMs from WT and CD226KO mice fed with HFD. We found that the glycolysis capacity (i.e., real-time extracellular acidification rate, ECAR) of the ATMs was limited in the HFD CD226KO group (Fig. 4D). This result is consistent with the previous conclusion that M1-type ATMs are decreased in obese CD226KO mice.

To mimic the inflammatory state of common macrophages after HFD, peritoneal macrophages from WT and CD226KO mice were isolated and cultured for $12 \mathrm{~h}$ with LPS stimulation. The qPCR results showed that in CD226KO macrophages, M1-type proinflammatory markers such as $I l-1 \beta, I l-6, I l-12, i N O S, M c p-1$, Tnf- $\alpha$, Ccl3, Cxcl14, and Cxcl16 reduced significantly, while M2-related molecules, including Arg1, Ym-1, and PPAR- $\gamma$ increased (Fig. 5A). Consistent with the ATM metabolic results, CD226KO peritoneal macrophages exhibited a lower glycolysis capacity than WT controls (Fig. 5B). Interestingly, ROS production decreased in CD226KO macrophages, as shown by staining cells with mitochondrial superoxide indicator MitoSOX, implying that the inflammatory phenotype of CD226KO macrophages was suppressed (Fig. 5C).

\section{CD226 regulates macrophage polarization through PPAR- $\gamma$-related signaling}

PPAR $-\gamma$ is a critical transcription factor that is required for the alternative activation and suppression of the inflammatory macrophages [22]. We found that PPAR- $\gamma$ expression was upregulated in the epididymal SVF of HFD-fed CD226KO mice compared with the WT (Fig. 6A, B). Previous studies have shown that VAV1 is responsible for CD226 signaling transduction in NK and $\mathrm{CD}^{+} \mathrm{T}$ cells [23-25]. A recent study also reported that CD226 contributes to phosphorylation-mediated Forkhead box protein O1 (FOXO1) inactivation in NK cells [26]. As AKT is responsible for phosphorylation-mediated FOXO1 inactivation, we found that CD226 deficiency suppressed the phosphorylation and activation of VAV1 and AKT (Fig. 6C), which also led to suppressed FOXO1 inactivation and degradation and further upregulated FOXO1-dependent PPAR- $\gamma$ expression (Fig. 6C). Direct evidence from the dual-luciferase reporter assay additionally supports the regulation of CD226 on FOXO1/PPAR- $\gamma$ signaling in RAW264.7 cells. As shown in Fig. 6D, the luciferase activity of the pGL3-PPAR- $\gamma$ promoter was significantly increased following administration of CD226-specific antibody (Clone, \#10E5), which indicated that CD226 blocking weakened the binding effects of FOXO1 on PPAR- $\gamma$ promoter. These in vitro results support that CD226 deficiency regulates PPAR- $\gamma$ activation.

To confirm this regulation, we used the PPAR$\gamma$-specific inhibitor GW9662 to block its signal in

(See figure on next page.)

Fig. 2 Obesity was ameliorated in HFD-fed CD226KO mice. A Representative images of WT and CD226KO mice fed with a HFD for 16 weeks $(n=6)$. B Bodyweight of WT and CD226KO mice fed with either chow or a HFD for 16 weeks $(n=4)$. C Representative H\&E staining and perilipin-1 immunofluorescence staining of epididymal fat of WT and CD226KO mice fed with either chow or a HFD for 16 weeks ( $n=4$ ). Scale bar means $100 \mu \mathrm{m}$. D Adipocyte size and measurements of epididymal fat of WT and CD226KO mice fed with either chow or a HFD for 16 weeks. ( $\mathrm{n}=4$ ). $\mathbf{E}, \mathbf{F}$ Representative H\&E images and islet size measurement of pancreatic tissue of WT and CD226KO mice fed with either chow or a HFD for 16 weeks. Scale bar means $100 \mu \mathrm{m}$. G Serum concentrations of triglyceride, HDL-C, LDL-C, and total cholesterol $(n=4)$. Graphs or combined data from three independent experiments. Data represent mean \pm SEM. Differences between groups were determined by one way ANOVA with Tukey's multiple test. ${ }^{*} P<0.05,{ }^{* *} P<0.01$ 


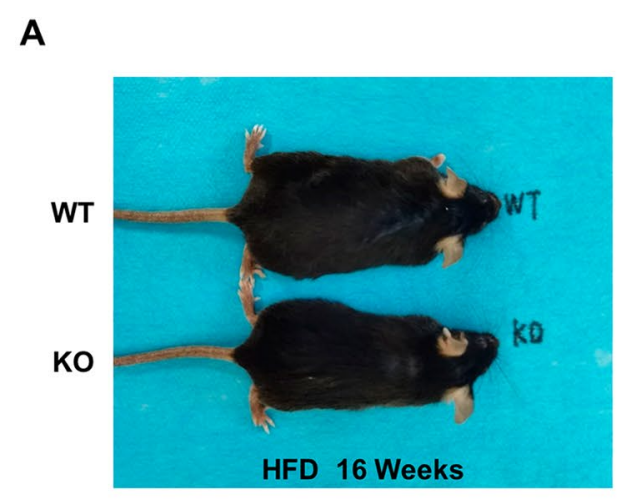

\section{H\&E staining}

B
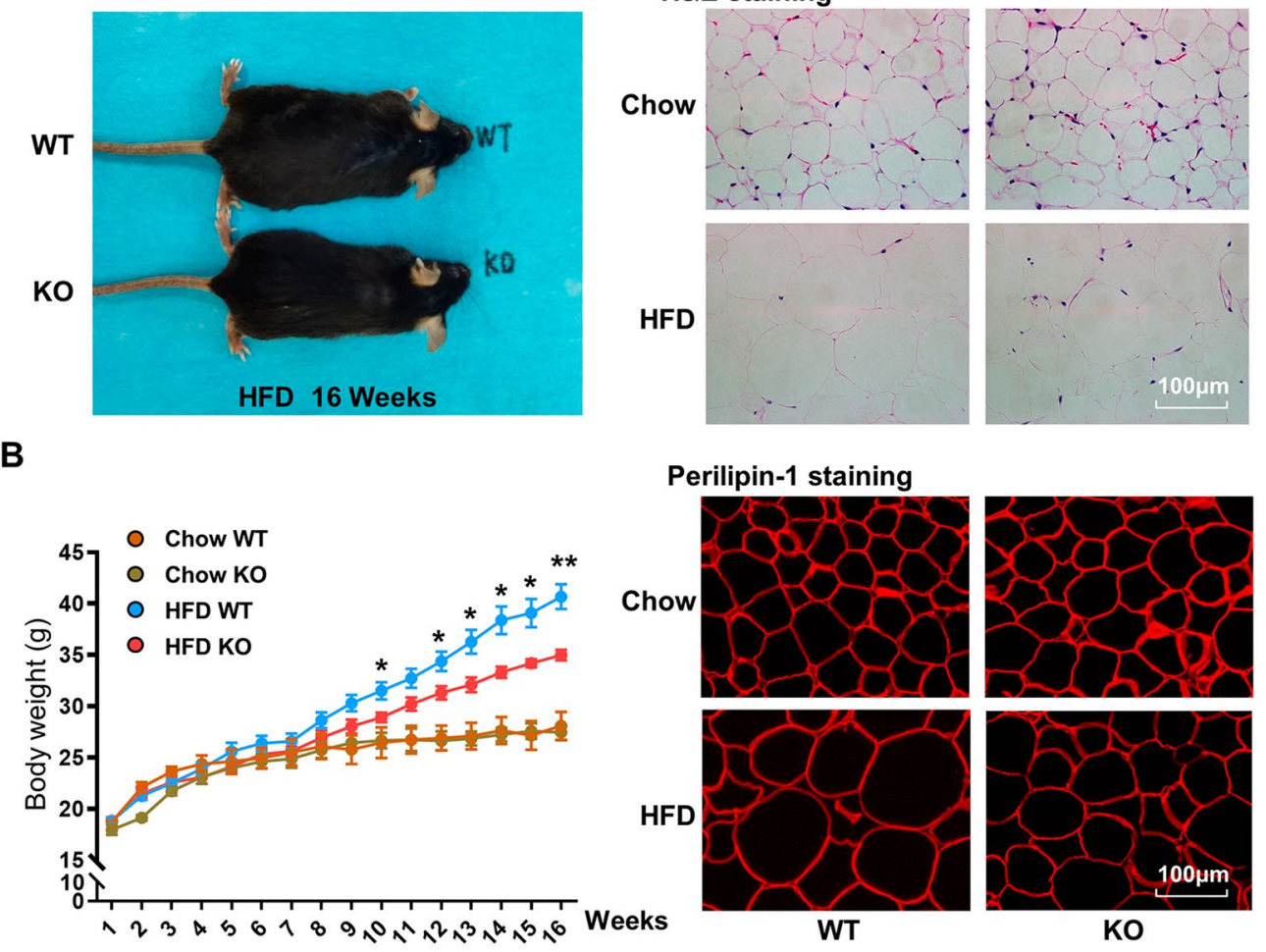

Perilipin-1 staining

D

E
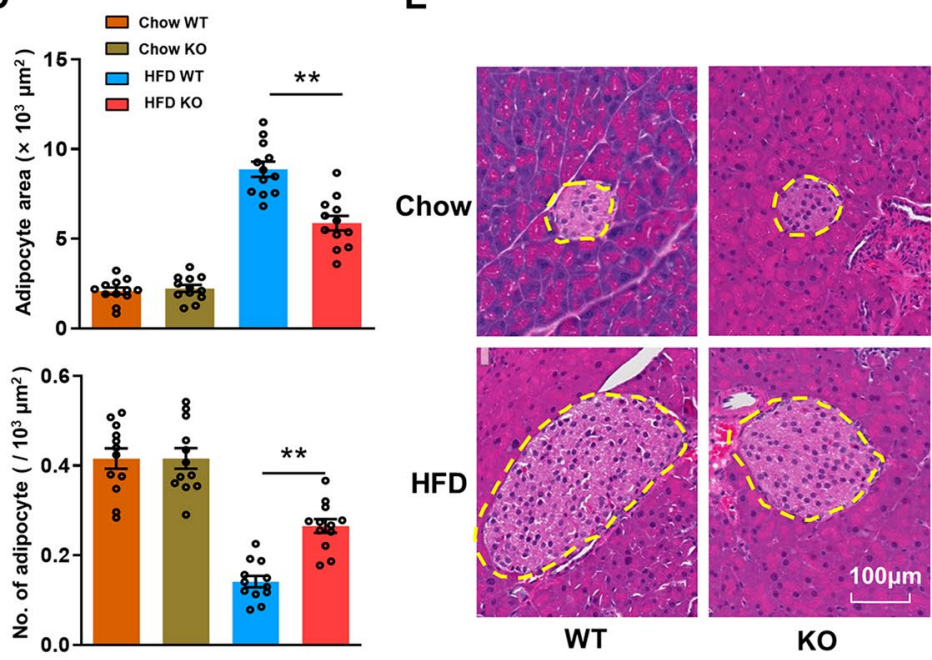

$\mathbf{F}$
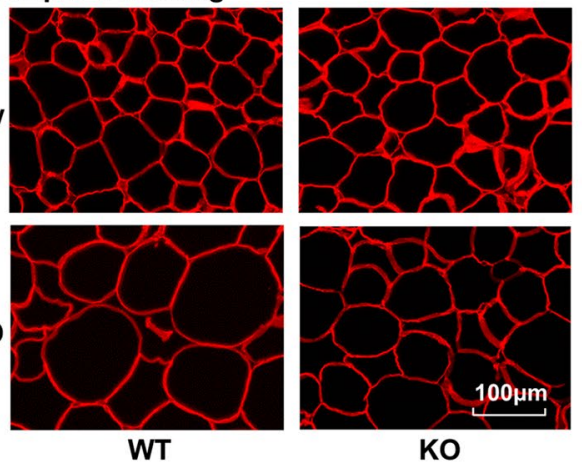

G
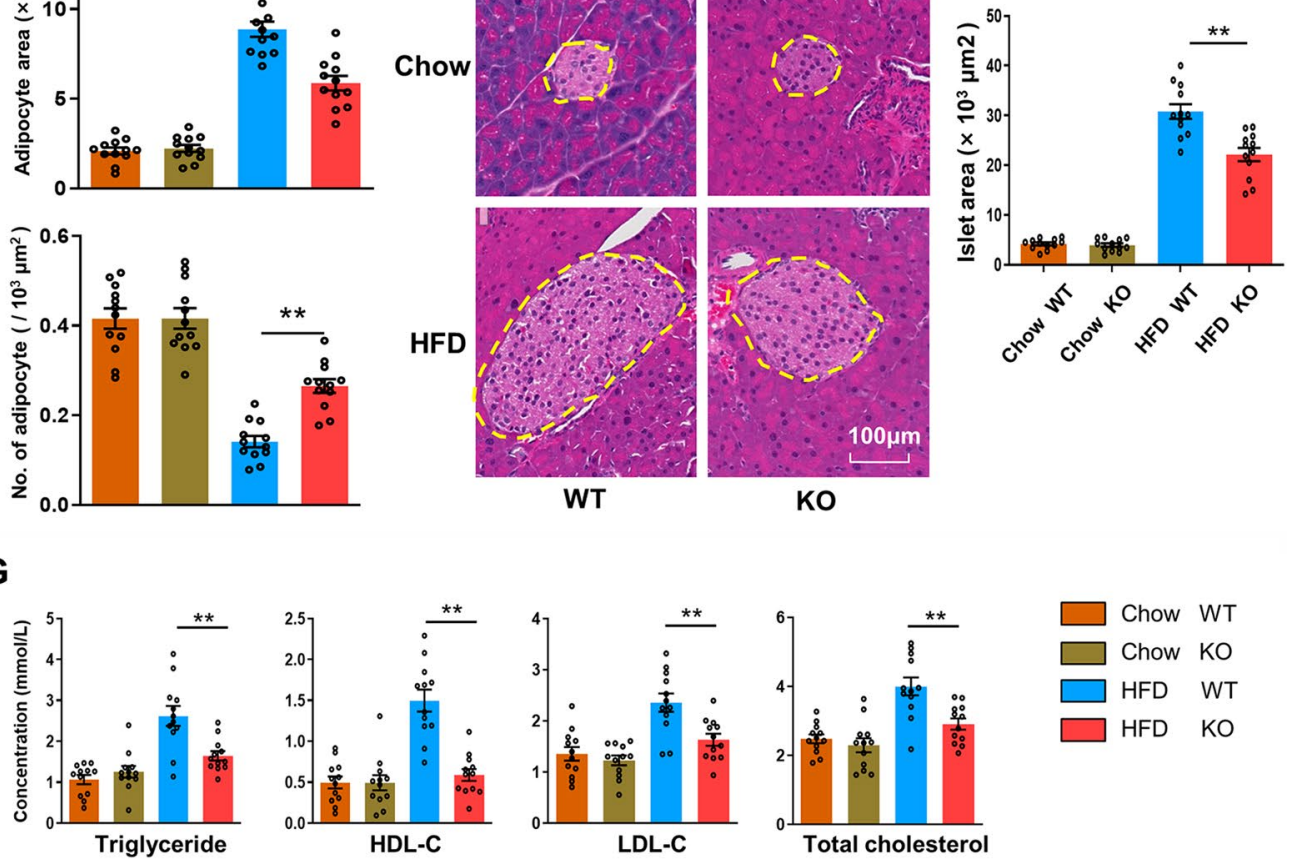

Fig. 2 (See legend on previous page.) 

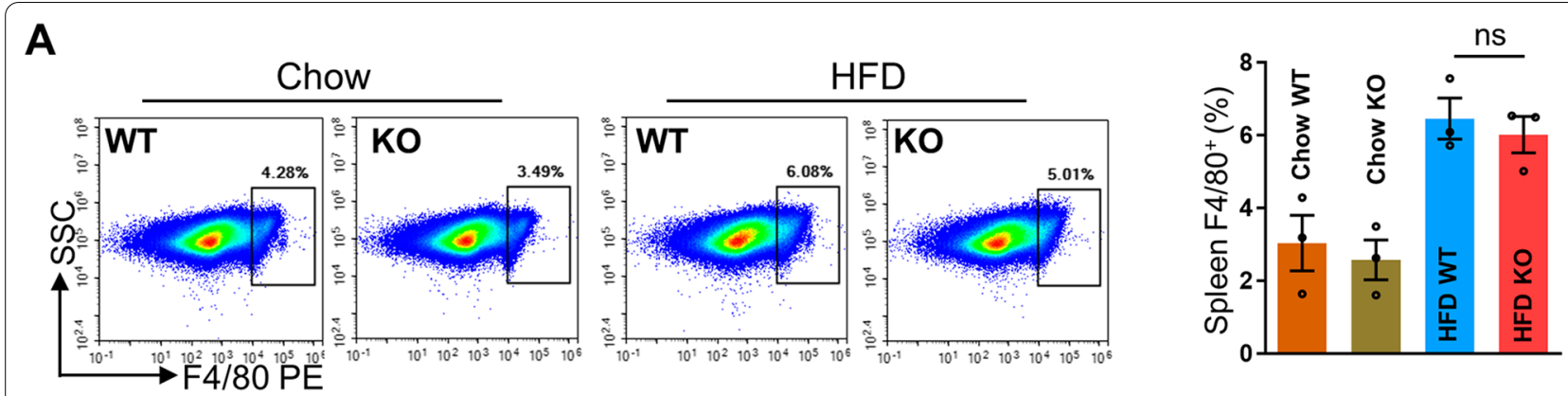

B
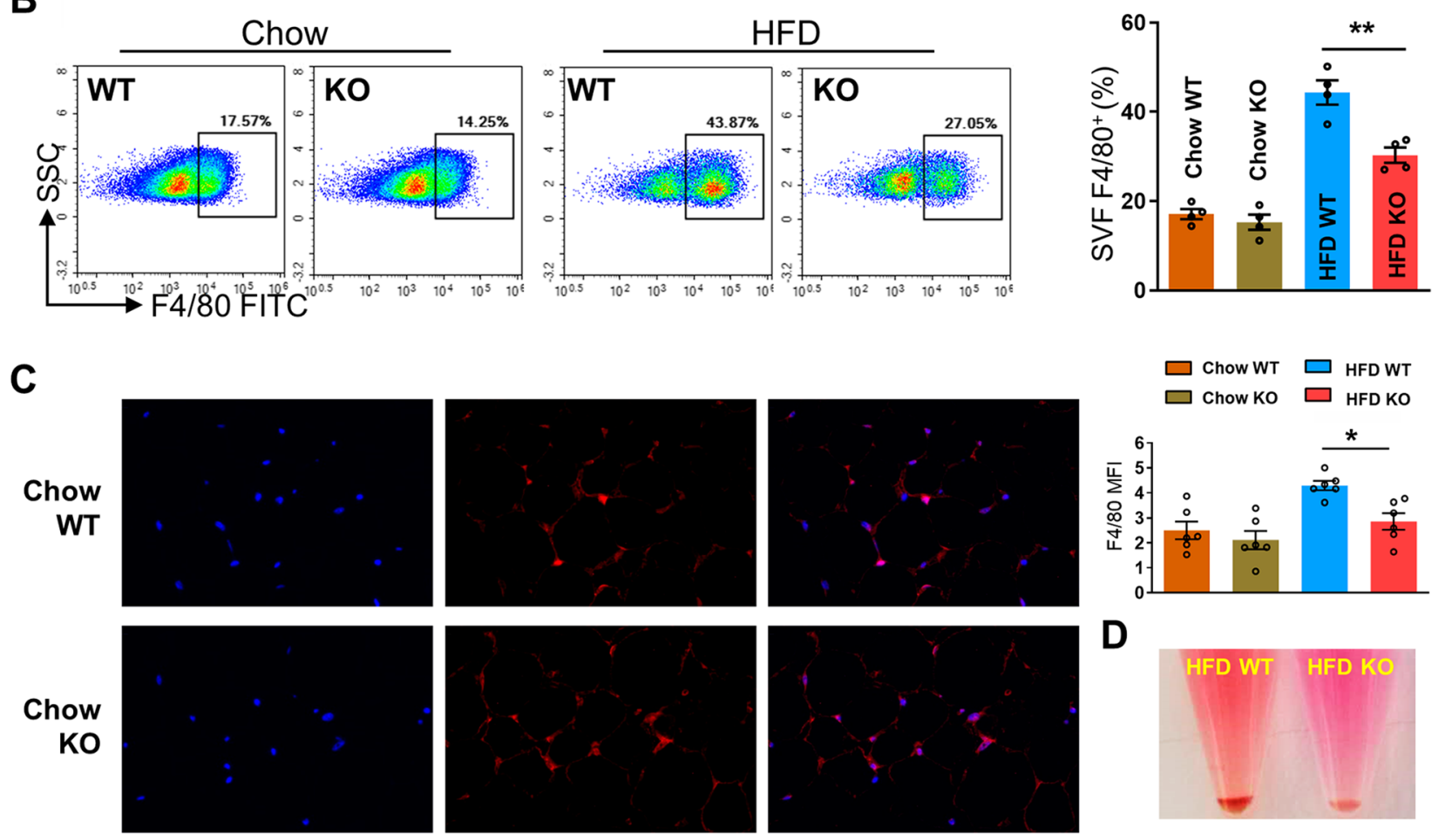

D
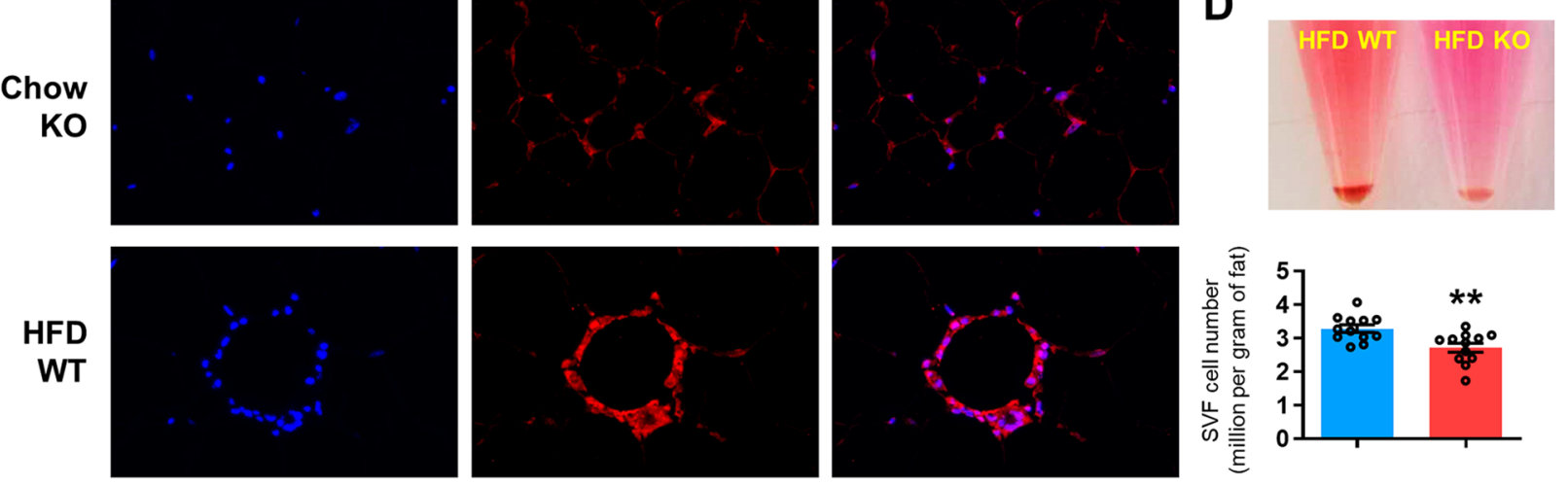

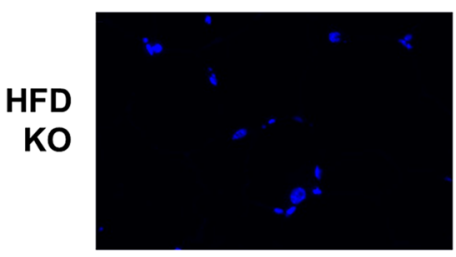

DAPI

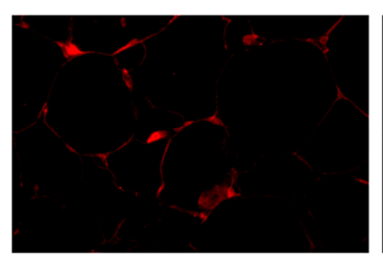

$\mathrm{F} 4 / 80$

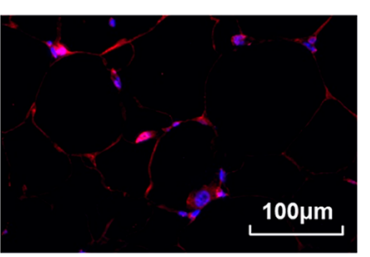

Merge

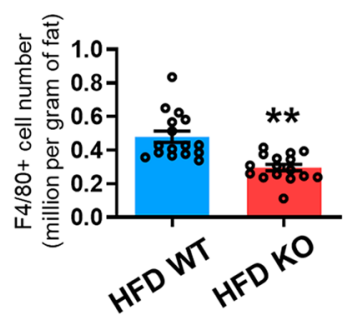

Fig. 3 Decrease of ATMs in HFD-fed CD226KO mice. A FACS analysis of F4/80+ macrophages in the spleens of WT and CD226KO mice fed with either chow or a HFD for 16 weeks $(n=3)$. B FACS analysis of $\mathrm{F} 4 / 80^{+}$macrophages in epididymal SVF $(n=4)$. C Representative images and quantification of immunofluorescence staining of F4/80 in the epididymal fat of WT and CD226KO mice $(n=4)$. Scale bar means $100 \mu m$. D Gross images and absolute cell count of epididymal SVF cells and F4/80+ macrophages obtained from groups of mice fed with chow or a HFD ( $n=4)$. Combined data from three independent experiments. Data represent mean \pm SEM. Differences between groups were determined by one way ANOVA with Tukey's multiple test $(\mathbf{A}, \mathbf{B})$ or unpaired Student's t-test (D). ${ }^{*} P<0.05,{ }^{*} P<0.01$ 
LPS-stimulated macrophages from CD226KO mice. The previously reduced expression of proinflammatory factors in CD226KO mice (vehicle), including $\mathrm{Il}-1 \beta, \mathrm{Il}-6$, Il-12, Mcp-1, Ccl3, Cxcl14, and Cxcl16, increased significantly upon PPAR- $\gamma$ inhibitor treatment (Fig. 6E). Meanwhile, the increased M2-type markers such as Fizz1, Il-10, and Arg1 was also reduced by GW9662 (Fig. 6E). The concentration of proinflammatory cytokines in the CD226KO macrophage culture supernatant increased significantly in the GW9662 group (Fig. 6F). As shown in Fig. 6G M1 polarization of CD226KO macrophages (detected by CD11c) was also elevated by the PPAR- $\gamma$ inhibitor. These results confirm that the suppressive effect of CD226 deficiency on these cytokines and chemokines was dependent on PPAR- $\gamma$.

\section{Discussion}

HFD has been shown to induce obesity and metabolic inflammation [27]. The associations between HFD and metabolic diseases, including obesity, cardiometabolic diseases, and NALFD, have attracted increasing attentions [28-30]. Recent research has established the emerging importance of immune cells in the metabolic homeostasis [31-33]. Thus, exploring the immunological mechanisms of metabolic inflammation induced by a HFD is urgently warranted. In the present study, we clarified the potential roles of CD226 in HFD-induced obesity and its related systemic inflammation.

Previous studies have shown that $C d 226$ gene polymorphism is associated with the incidence of type 1 diabetes. The $\mathrm{T}$ allele of the $C d 226$ rs763361 polymorphism is associated with a higher susceptibility to diabetes, lower onset age, and greater aggressiveness of the disease [3437]. Our previous study showed that CD226 on endothelial cells contributes to hyperglycemia in type 2 diabetes mellitus by suppressing glucose uptake in endothelial cells[9]. This indicates potential roles of CD226 in obesity-associated metabolic diseases. However, the exact roles of CD226 in chronic inflammatory disorders have not yet been fully elucidated.

The function of CD226 on T and NK cells has been widely studied, while its role in monocytes /macrophages was relatively less reported. Among them, CD226 was studied to be involved in the monocyte adhesion to CD155-expressing cells, such as endothelial cells. Administration of CD226 antibody could block the trans-endothelial migration of monocytes over endothelial junctions [7, 38, 39]. Another study showed that the expression of CD226 on inflammatory monocytes and splenic macrophages was increased after mouse cytomegalovirus infection. CD226 on monocytes/ macrophages interacted with CD155 on NK cells to control virus infection [40]. These publications indicated that CD226 functioned as a key interactor between monocytes/macrophages and CD155-expressing cells to modulate their migration. Moreover, recent studies indicated that CD226 exerted costimulatory effects on antigen presentation mediated by small peritoneal macrophages [11]. Deletion of CD226 further improved post-infarction healing and cardiac function by favoring macrophage polarization towards reparative phenotype [10]. These results suggested that CD226 on macrophages in different tissues may play distinct roles, which needs to be specifically studied with different surroundings.

Here, we observed that CD226 was highly expressed in the obesity population and ATMs. As the most abundant class of immune cell in adipose tissue, ATMs play a crucial role in the chronic inflammation associated with obesity [33]. The infiltration of ATMs is significantly increased in obese patients [20], and macrophage accumulation is positively correlated with the severity of adipose tissue inflammation and fatty liver [41]. Additionally, the balance of M1/M2 ATMs in obese individuals is significantly weighted toward M1 [20]. Regulating the alternative activation of ATMs could modulate obesity-associated systemic inflammation and metabolic dysfunction [42, 43]. However, exact roles of CD226 on ATMs during obesity and adipose tissue inflammation remain unclear. In this study, we found that ATM accumulation and polarization toward M1 were significantly suppressed in HFD-fed CD226KO mice. Moreover, the severity of HFD-induced obesity and its related systemic inflammation was significantly improved in CD226KO mice. Through in vivo and in vitro experiments, we found that CD226-deficient ATMs exhibited suppressed M1 polarization, lower glycolysis capacity, and reduced ROS production, suggesting that CD226 deficiency inhibited ATM polarization towards proinflammatory phenotype.

Transcription factor profiling is essential to understand the mechanisms of macrophage function and heterogeneity. PPAR- $\gamma$ is a vital transcription factor with diverse functions, such as regulation of adipocyte differentiation

\footnotetext{
(See figure on next page.)

Fig. 4 The proinflammatory ATM phenotype was reduced in HFD-fed CD226KO mice. A Serum concentrations of M1-type cytokines and chemokines in WT and CD226KO mice fed with chow or a HFD for 16 weeks $(n=6)$. B FACS analysis of M1-type (CD1 1c $\left.{ }^{+}\right)$ATMs from WT and CD226KO mice with a HFD $(n=4)$. C mRNA levels of M1/M2-type markers and chemokines in epididymal ATMs from HFD WT and CD226KO mice $(n=3)$. D Glycolytic activity of ATMs from HFD WT and CD226KO mice $(n=3)$ Combined data from three independent experiments. 2-DG, 2-deoxyglucose. Data represent mean \pm SEM. Differences between groups were determined by one way ANOVA with Tukey's multiple test (A, C, D) or unpaired Student's t-test $(\mathbf{B}) .{ }^{*} \mathrm{P}<0.05,{ }^{* *} \mathrm{P}<0.01$
} 


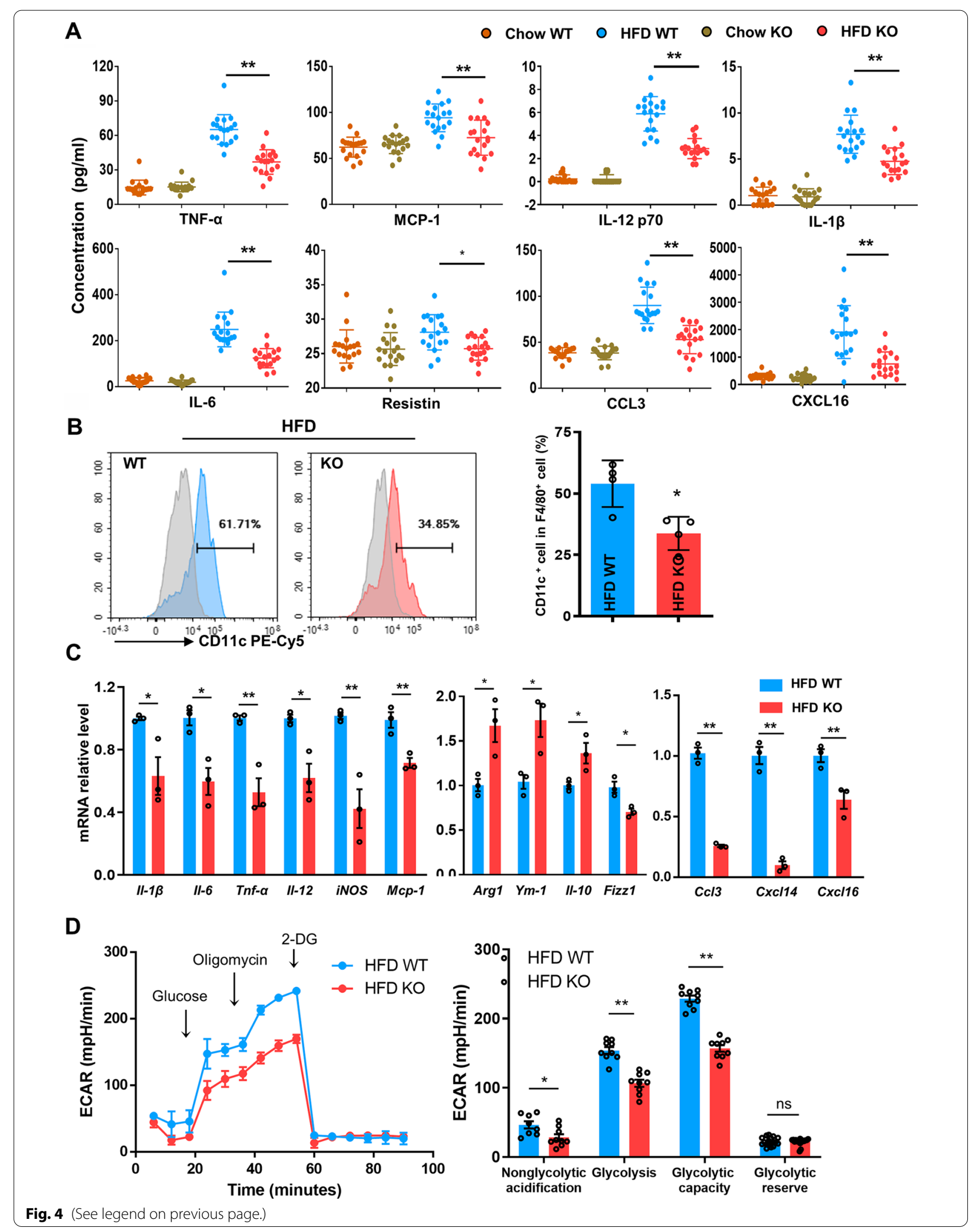




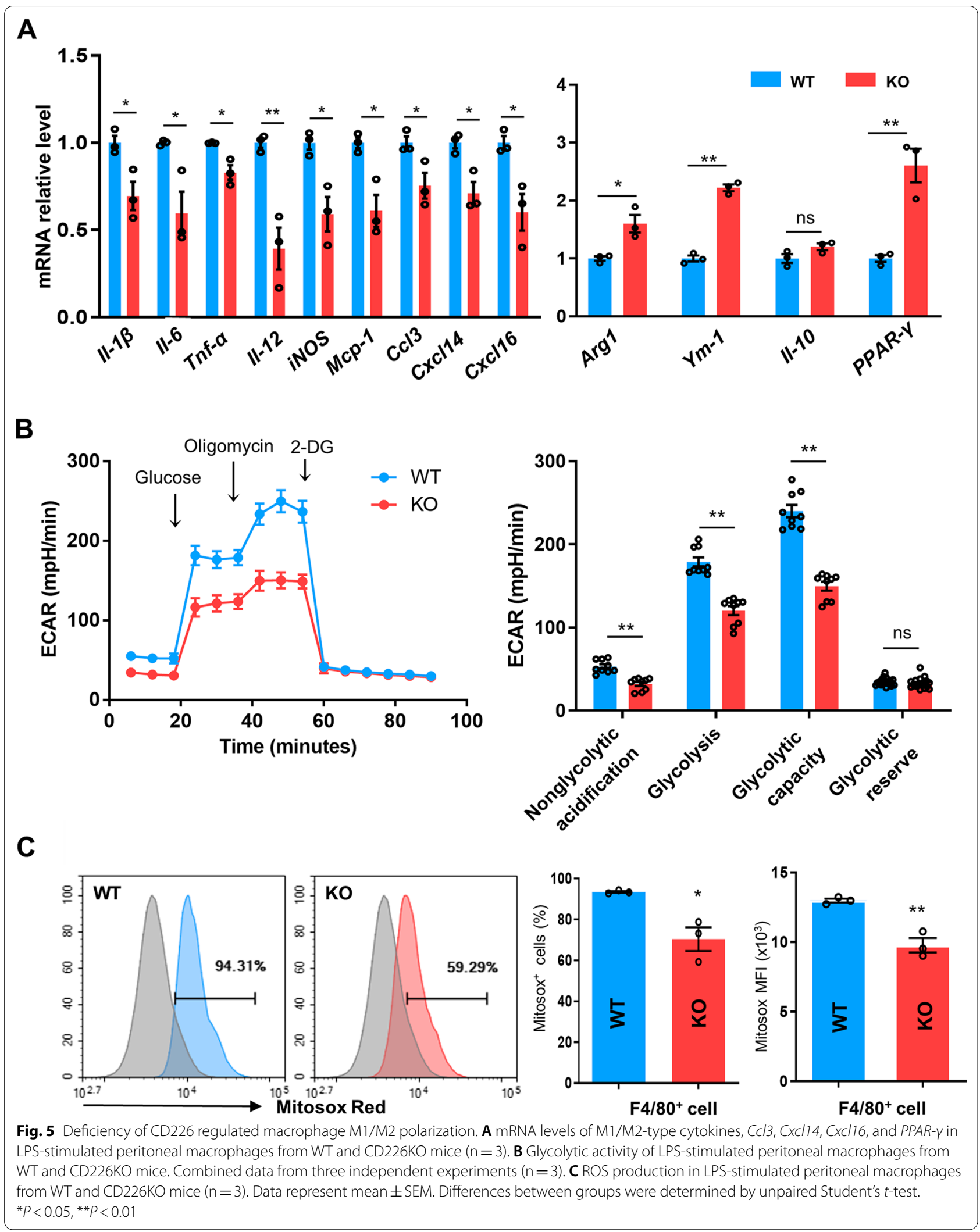




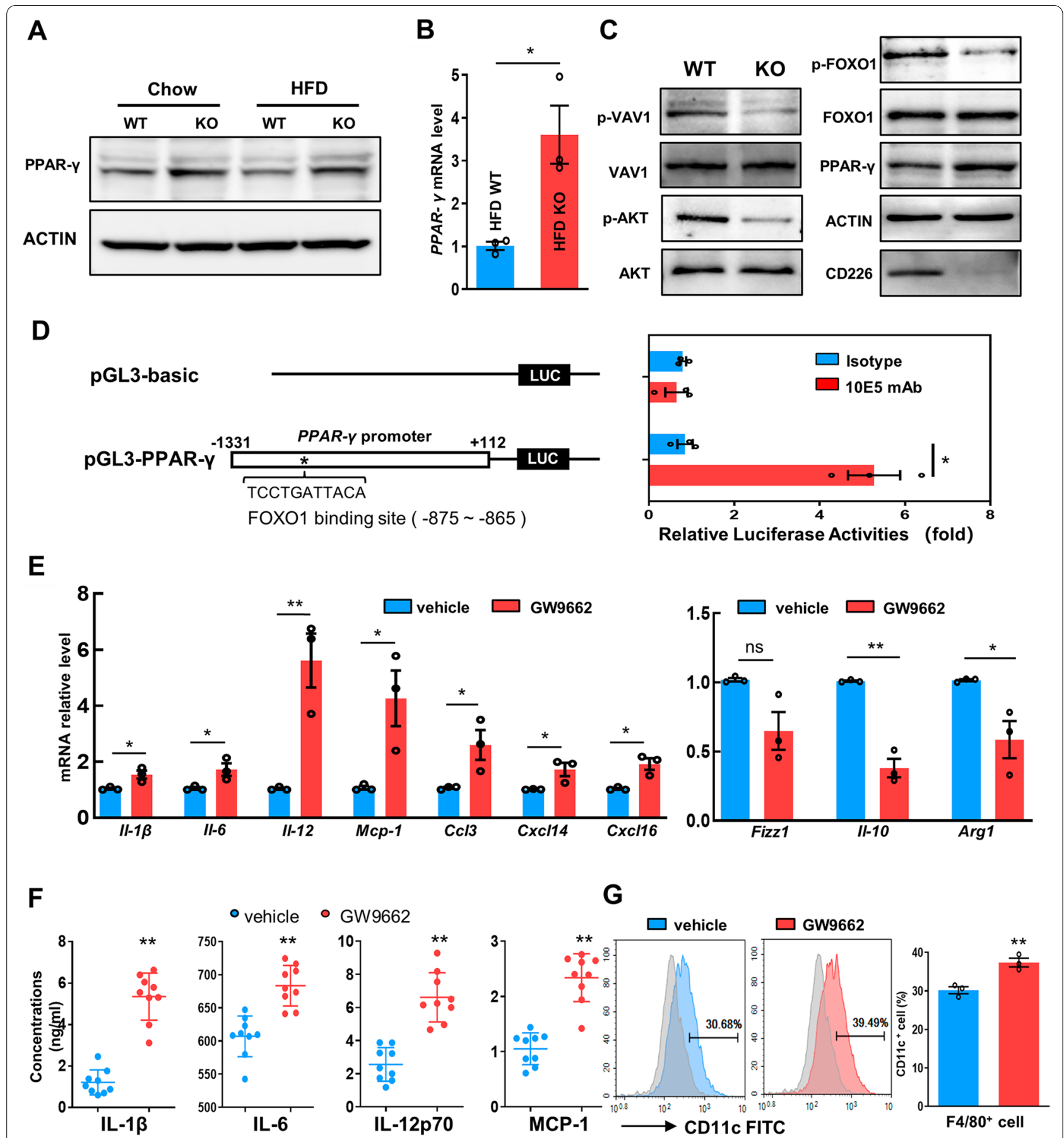

Fig. 6 VAV1-AKT-FOXO1-PPAR- $\gamma$ pathway was involved in the regulation of CD226KO on macrophage polarization. A Immunoblot analysis of the expression of PPAR- $\gamma$ in the epididymal fat of WT and CD226KO mice fed with either chow or a HFD for 16 weeks. Blots are representative of three independent experiments. B mRNA levels of PPAR-y in epididymal SVF from WT and CD226KO mice on a HFD ( $n=3)$. C Immunoblot analysis of the expression of p-VAV1, VAV1, p-AKT, AKT, p-FOXO1, FOXO1, and PPAR- $\gamma$ in peritoneal macrophages from WT or CD226KO mice. Blots are representative of three independent experiments. $\mathbf{D}$ Luciferase activities were measured in RAW264.7 cells transfected with pGL3-PPAR- $\gamma$ or pGL3-basic plasmids following 10E5 or isotype antibody treatment $(n=3)$. E mRNA levels of M1/M2-type cytokines and chemokines in LPS-stimulated CD226KO peritoneal macrophages treated with the PPAR- $\gamma$ specific inhibitor GW9662 or DMSO vehicle control $(n=3)$. F Culture supernatant concentrations of proinflammatory cytokines in LPS-stimulated CD226KO peritoneal macrophages treated with GW9662. Combined data from three independent experiments $(n=3)$. G FACS analysis of CD11 $\mathrm{C}^{+} \mathrm{M} 1$ in LPS-stimulated CD226KO peritoneal macrophages treated with GW9662 $(n=3)$. Data represent mean \pm SEM. Differences between groups were determined by one way ANOVA with Tukey's multiple test (D) or unpaired Student's $t$-test $(\mathbf{B}, \mathbf{E}, \mathbf{F}, \mathbf{G}) .{ }^{*} P<0.05,{ }^{* *} P<0.01$ 
and glucose homeostasis [44]. A previous study showed that PPAR- $\gamma$ is required for alternative activation, i.e., M2 activation of macrophages [45]. In particular, activation of PPAR- $\gamma$ suppresses NF- $\kappa B$ signaling and the inflammatory response genes, thus inhibiting the activation of M1 macrophages, and shifts the M1/M2 balance toward M2 macrophages [46, 47]. In the present study, we found that the activity of PPAR- $\gamma$ was significantly increased in CD226KO ATMs, accompanied by suppressed M1 macrophage activity. Furthermore, M1 phenotype was reversed in CD226KO ATMs upon administration of PPAR- $\gamma$ inhibitor.

We shed light on the molecular mechanisms of CD226 signaling transduction in macrophages and investigated why CD226 is negatively corrected with PPAR- $\gamma$ expression. Previous studies have shown that VAV1 mediates the transduction of CD226 signaling in NK and CD4 ${ }^{+}$ $\mathrm{T}$ cells [23-25]. VAV1 is responsible for the phosphorylation of Akt and FOXO1 in T cells [48]. Phosphorylated FOXO1 would translocate from the nucleus to the cytoplasm, where it degrades [49]. Another study found that FOXO1 is responsible for the expression of PPAR $\gamma$ [50]. We found that when CD226 signaling was deficient or blocked, VAV1 and AKT phosphorylation was suppressed; suppressed AKT phosphorylation led to reduced FOXO1 phosphorylation, then the inactivation and degradation of FOXO1 were inhibited, causing increased FOXO1-dependent PPAR- $\gamma$ expression. The potential underlying mechanisms of ATM involvement in systematic metabolic disorders have been clarified in the present study. Bijnen et al. showed that CD11 ${ }^{+}$ ATMs secrete CXCL14 and CXCL16 to recruit neutrophils and macrophages in the liver, which ultimately contributes to the development of fatty liver [21]. Moreover, ATM-secreted CCL3 is positively associated with the histological severity of fatty liver [1]. PPAR $\gamma$ has been found to attenuate the production and secretion of these chemokine receptors/ligands [51-54]. Combined with these literatures, the elevated PPAR- $\gamma$ activation caused by CD226 deficiency may also partially contribute to the ameliorated obesity-related fatty liver through suppression of chemokines.

In conclusion, we proposed that CD226 deficiency could alleviate the severity of HFD-induced obesity via inhibition of the accumulation and M1 polarization of ATMs and secretion of proinflammatory cytokines. We also clarified that PPAR- $\gamma$-dependent signaling pathway is involved in the CD226-affected ATM activation (Fig. 7). Combined with the highly expressed CD226 in the obesity patients, our findings support the use of antiCD226 for the treatment of obesity and its related metabolic disorders.

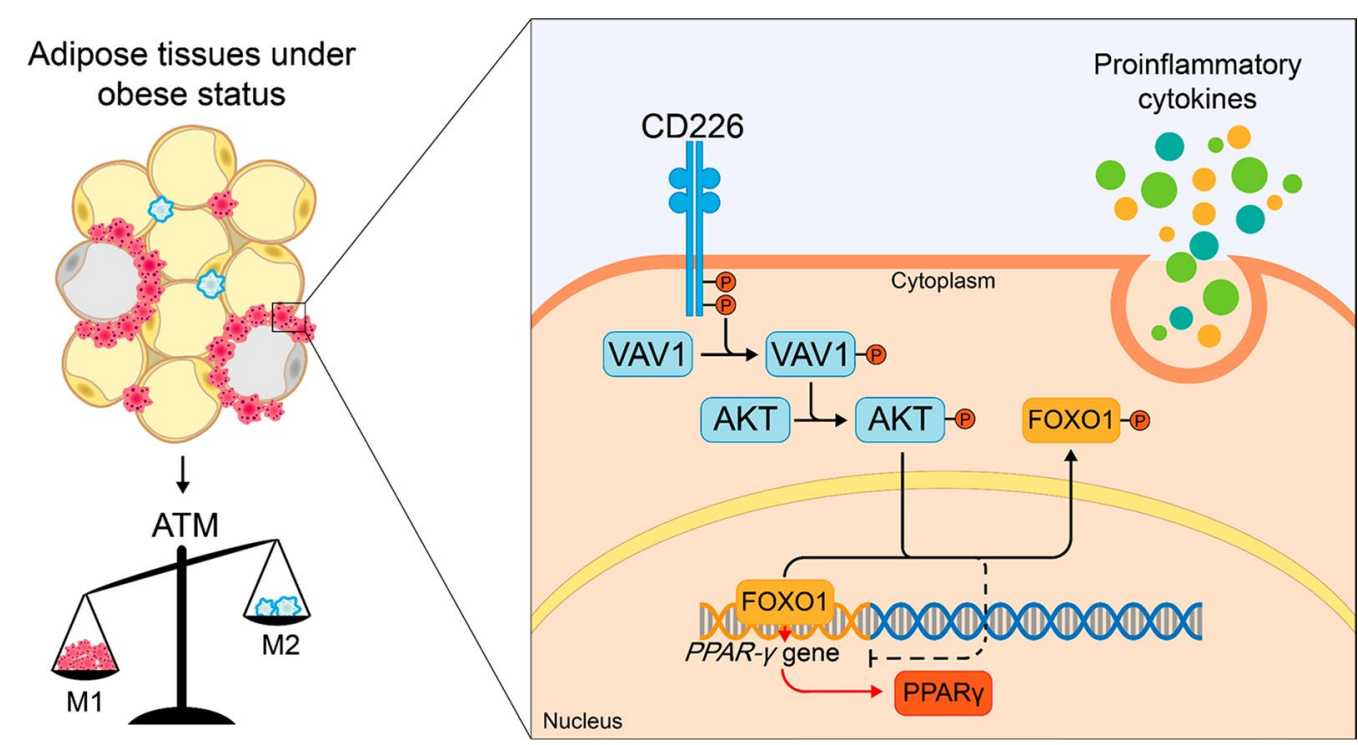

Fig. 7 CD226 modulates the ATM polarization under a model of HFD-induced obesity. CD226 affects macrophage accumulation in adipose tissues and mediates macrophage M1 polarization. Proinflammatory M1-type ATMs induce the development of inflammation within adipose tissue and contribute to systemic inflammatory state, including fatty liver, by secreting proinflammatory cytokines through PPAR- $\gamma$-dependent signaling, which leads to the occurrence and progress of obesity 


\section{Abbreviations}

ATM: Adipose tissue macrophages; HFD: High-fat diet; KO: Knockout; PPAR: Peroxisome proliferator-activated receptor; IQR: Interquartile range; SVF: Stromal vascular fraction; WT: Wildtype; H\&E: Hematoxylin and eosin; ORO: Oil Red O; ECAR: Extracellular acidification rate; FOXO1: Forkhead box protein O1; BMI: Body mass index; mAbs: Monoclonal antibodies; HRP: Horseradish peroxidase; FBS: Fetal bovine serum; SEM: Standard error.

\section{Supplementary Information}

The online version contains supplementary material available at https://doi. org/10.1186/s12967-021-03150-4.

Additional file 1: Figure S1. Expression of macrophage CD226 increased under inflammatory conditions. (A) Cd226 mRNA levels in the epididymal fat and SVF of mice fed chow or a HFD for 16 weeks. (B) FACS analysis of CD226 expression on NK, CD4+, and CD8+ cells in the epididymal SVF of mice fed chow or a HFD for 16 weeks. (C) FACS analysis of CD155 expression on macrophages in the epididymal SVF of mice fed chow or a HFD for 16 weeks. (D) FACS analysis of CD226 expression on macrophages in mouse livers. (E) FACS analysis of CD226 expression on RAW264.7 cells with or without LPS stimulation. $\mathrm{N}=3$. Data represent mean $\pm \mathrm{SEM}$. Intergroup differences were determined by unpaired Student's t-test. ${ }^{*} \mathrm{P}<$ $0.05,{ }^{* *} \mathrm{P}<0.01$.

Additional file 2: Figure S2. (A) Representative image of CD226KO mice identification by genotyping PCR.

Additional file 3: Figure S3. Obesity-related fatty liver was alleviated in HFD-fed CD226KO mice. (A) Serum concentrations of AST, ALT, $Y$-GT, and ALP. Combined data from three independent experiments $(n=4$ mice per group). (B) Representative liver images from WT or CD226KO mice and (C) the relative weight of the livers. Combined data from three independent experiments ( $n=6$ mice per group). (D) Representative images of ORO staining and quantification of positive area. Graphs from three independent experiments ( $n=6$ mice per group). Scale bar means $200 \mu m$. (E) Representative images of H\&E staining of livers from WT and CD226KO mice. Three independent experiments were performed ( $n=7$ mice per group). Scale bar means $200 \mu \mathrm{m}$ and $50 \mu \mathrm{m}$. All of these samples were obtained from WT and CD226KO mice fed with chow or a HFD for 16 weeks. Data represent mean \pm SEM. Differences between groups were determined by one way ANOVA with Tukey's multiple test. ${ }^{*} P<0.05,{ }^{* *} P<0.01$.

Additional file 4: Figure S4. (A) In HFD-induced obesity mice, CD226KO had no significant effect on the proportion of CD4+, CD8+ and NK cells in white adipose tissues. Representative FACS images in each group were shown.

Additional file 5: Figure S5. (A) Concentrations of proinflammatory cytokines and chemokines in culture supernatants of HFD WT and CD226KO mice ATMs. Combined data from three independent experiments $(n=3)$. Data represent mean \pm SEM. Intergroup differences were determined by unpaired Student's t-test. ${ }^{*} P<0.05$, ${ }^{*} P<0.01$.

Additional file 6: Table S1. Basic information for clinical participants. Table S2. The sequences of the qPCR primers.

\section{Acknowledgements}

Not applicable.

\section{Authors' contributions}

JCM, WH, and RZ: Conceptualization; JCM, DLZ, YTL, YZ, and RZ designed methodology; JCM, WH, JGX, CJD, YLW, XXX, and KC performed investigation; writing of the original draft was performed by JCM and $Y Z ; C J D, Y Z$, and RZ reviewed and edited the draft; funding acquisition was done by $B Q J, Y Z$, and $R Z$; RZ managed the project; and supervision was provided by $Y Z$ and RZ. All authors have read and approved the final manuscript.

\section{Funding}

This work was supported by the Natural Science Foundation of China (No. 81871258 ) and the Basic research program of Natural Science in Shaanxi Province (No. 2021JM-081)

\section{Availability of data and materials}

The datasets used and/or analysed during the current study are available from the corresponding author on reasonable request.

\section{Declarations}

Ethics approval and consent to participate

All procedures of clinical sample collection were approved by the Tangdu Hospital ethics committee and conformed with the principles of Helsinki Declaration, and all participants provided written and/or oral informed consent. All animal experiments were approved by the Institutional Animal Care and Use Committee of the Fourth Military Medical University.

\section{Consent for publication}

Not applicable.

\section{Competing interests}

The authors declare that they have no competing interests.

Received: 30 September 2021 Accepted: 17 November 2021

Published online: 25 November 2021

\section{References}

1. Du Plessis J, van Pelt J, Korf H, Mathieu C, van der Schueren B, Lannoo M, et al. Association of adipose tissue inflammation with histologic severity of nonalcoholic fatty liver disease. Gastroenterology. 2015;149:635-48 e14.

2. Reilly SM, Saltiel AR. Adapting to obesity with adipose tissue inflammation. Nat Rev Endocrinol. 2017;13:633-43.

3. Kratz M, Coats BR, Hisert KB, Hagman D, Mutskov V, Peris E, et al. Metabolic dysfunction drives a mechanistically distinct proinflammatory phenotype in adipose tissue macrophages. Cell Metab. 2014;20:614-25.

4. Murray PJ, Allen JE, Biswas SK, Fisher EA, Gilroy DW, Goerdt S, et al. Macrophage activation and polarization: nomenclature and experimental guidelines. Immunity. 2014;41:14-20.

5. Serbulea V, Upchurch CM, Schappe MS, Voigt P, DeWeese DE, Desai $\mathrm{BN}$, et al. Macrophage phenotype and bioenergetics are controlled by oxidized phospholipids identified in lean and obese adipose tissue. Proc Natl Acad Sci USA. 2018;115:E6254-63.

6. Tahara-Hanaoka S, Miyamoto A, Hara A, Honda S, Shibuya K, Shibuya A. Identification and characterization of murine DNAM-1 (CD226) and its poliovirus receptor family ligands. Biochem Biophys Res Commun. 2005;329:996-1000

7. Kim KW, Williams JW, Wang YT, Ivanov S, Gilfillan S, Colonna M, et al. MHC $11+$ resident peritoneal and pleural macrophages rely on IRF4 for development from circulating monocytes. J Exp Med. 2016;213:1951-9.

8. $\mathrm{Xu} Z$, Jin B. A novel interface consisting of homologous immunoglobulin superfamily members with multiple functions. Cell Mol Immunol. 2010:7:11-9.

9. Zhang Y, Liu T, Chen Y, Dong Z, Zhang J, Sun Y, et al. CD226 reduces endothelial cell glucose uptake under hyperglycemic conditions with inflammation in type 2 diabetes mellitus. Oncotarget. 2016;7:12010-23.

10. Li J, Song Y, Jin JY, Li GH, Guo YZ, Yi HY, et al. CD226 deletion improves post-infarction healing via modulating macrophage polarization in mice. Theranostics. 2020;10:2422-35.

11. Takenaka E, Van Vo A, Yamashita-Kanemaru Y, Shibuya A, Shibuya K. Selective DNAM-1 expression on small peritoneal macrophages contributes to CD4(+) T cell costimulation. Sci Rep. 2018;8:15180.

12. Gilfillan S, Chan CJ, Cella M, Haynes NM, Rapaport AS, Boles KS, et al. DNAM-1 promotes activation of cytotoxic lymphocytes by nonprofessional antigen-presenting cells and tumors. J Exp Med. 2008;205:2965-73.

13. Goodrich JK, Di Rienzi SC, Poole AC, Koren O, Walters WA, Caporaso JG, et al. Conducting a microbiome study. Cell. 2014;158:250-62.

14. Caruso R, Ono M, Bunker ME, Nunez G, Inohara N. Dynamic and asymmetric changes of the microbial communities after cohousing in laboratory mice. Cell Rep. 2019;27:3401-12 e3.

15. Xu Z, Zhang T, Zhuang R, Zhang Y, Jia W, Song C, et al. Increased levels of soluble CD226 in sera accompanied by decreased membrane CD226 
expression on peripheral blood mononuclear cells from cancer patients. BMC Immunol. 2009;10:34.

16. Liu T, Zhang D, Zhang Y, Xu X, Zhou B, Fang L, et al. Blocking CD226 promotes allogeneic transplant immune tolerance and improves skin graft survival by increasing the frequency of regulatory $T$ cells in a murine model. Cell Physiol Biochem. 2018;45:2338-50.

17. Song Y, Wang B, Song R, Hao Y, Wang D, Li Y, et al. T-cell immunoglobulin and ITIM domain contributes to CD8(+) T-cell immunosenescence. Aging Cell. 2018. https://doi.org/10.1111/acel.12716.

18. Konner AC, Janoschek R, Plum L, Jordan SD, Rother E, Ma X, et al. Insulin action in AgRP-expressing neurons is required for suppression of hepatic glucose production. Cell Metab. 2007;5:438-49.

19. Heng TS, Painter MW, Immunological Genome Project C. The Immunological Genome Project: networks of gene expression in immune cells. Nat Immunol. 2008;9:1091-4.

20. Weisberg SP, McCann D, Desai M, Rosenbaum M, Leibel RL, Ferrante AW $\mathrm{Jr}$. Obesity is associated with macrophage accumulation in adipose tissue. J Clin Invest. 2003;112:1796-808.

21. Bijnen M, Josefs T, Cuijpers I, Maalsen CJ, van de Gaar J, Vroomen M, et al. Adipose tissue macrophages induce hepatic neutrophil recruitment and macrophage accumulation in mice. Gut. 2018;67:1317-27.

22. Okreglicka K, Iten I, Pohlmeier L, Onder L, Feng Q, Kurrer M, et al. PPARgamma is essential for the development of bone marrow erythroblastic island macrophages and splenic red pulp macrophages. J Exp Med. 2021. https://doi.org/10.1084/jem.20191314.

23. Zhang Z, Wu N, Lu Y, Davidson D, Colonna M, Veillette A. DNAM-1 controls NK cell activation via an ITT-like motif. J Exp Med. 2015;212:2165-82.

24. Gaud G, Roncagalli R, Chaoui K, Bernard I, Familiades J, Colacios C, et al. The costimulatory molecule CD226 signals through VAV1 to amplify TCR signals and promote IL-17 production by CD4(+) T cells. Sci Signal. 2018. https://doi.org/10.1126/scisignal.aar3083.

25. Kwon HJ, Choi GE, Ryu S, Kwon SJ, Kim SC, Booth C, et al. Stepwise phosphorylation of p65 promotes NF-kappaB activation and NK cell responses during target cell recognition. Nat Commun. 2016;7:11686.

26. Du X, de Almeida P, Manieri N, de Almeida ND, Wu TD, Harden Bowles K, et al. CD226 regulates natural killer cell antitumor responses via phosphorylation-mediated inactivation of transcription factor FOXO1. Proc Natl Acad Sci USA. 2018;115:E11731-40.

27. Giugliano D, Ceriello A, Esposito K. The effects of diet on inflammation: emphasis on the metabolic syndrome. J Am Coll Cardiol. 2006;48:677-85.

28. Tong M, Saito T, Zhai P, Oka SI, Mizushima W, Nakamura M, et al. Mitophagy is essential for maintaining cardiac function during high fat diet-induced diabetic cardiomyopathy. Circ Res. 2019;124:1360-71.

29. Rao A, Kosters A, Mells JE, Zhang W, Setchell KD, Amanso AM, et al. Inhibition of ileal bile acid uptake protects against nonalcoholic fatty liver disease in high-fat diet-fed mice. Sci Transl Med. 2016;8:357ra122.

30. Baufeld C, Osterloh A, Prokop S, Miller KR, Heppner FL. High-fat dietinduced brain region-specific phenotypic spectrum of CNS resident microglia. Acta Neuropathol. 2016;132:361-75.

31. Cai J, Zhang XJ, Li H. The Role of Innate Immune Cells in Nonalcoholic Steatohepatitis. Hepatology. 2019;70:1026-37.

32. Bedossa P. Pathology of non-alcoholic fatty liver disease. Liver Int. 2017:37(Suppl 1):85-9.

33. Lee BC, Kim MS, Pae M, Yamamoto Y, Eberle D, Shimada T, et al. Adipose natural killer cells regulate adipose tissue macrophages to promote insulin resistance in obesity. Cell Metab. 2016;23:685-98.

34. Abu El-Ella SS, Khattab E, El-Mekkawy MS, El-Shamy AA. CD226 gene polymorphism (rs763361 C>T) is associated with susceptibility to type 1 diabetes mellitus among Egyptian children. Arch Pediatr. 2018;25:378-82.

35. Kiani AK, John P, Bhatti A, Zia A, Shahid G, Akhtar P, et al. Association of 32 type 1 diabetes risk loci in Pakistani patients. Diabetes Res Clin Pract. 2015;108:137-42.

36. Xi JS, Nie CL, Wang J, Ma Y, Ma AH. Association of CD226 polymorphisms with the susceptibility to type 1 diabetes in Chinese children. Genet Mol Res. 2015;14:15249-55.
37. Mattana TC, Santos AS, Fukui RT, Mainardi-Novo DT, Costa VS, Santos RF, et al. CD226 rs763361 is associated with the susceptibility to type 1 diabetes and greater frequency of GAD65 autoantibody in a Brazilian cohort. Mediators Inflamm. 2014;2014:694948.

38. Sullivan DP, Seidman MA, Muller WA. Poliovirus receptor (CD155) regulates a step in transendothelial migration between PECAM and CD99. Am J Pathol. 2013;182:1031-42.

39. Reymond N, Imbert AM, Devilard E, Fabre S, Chabannon C, Xerri L, et al. DNAM-1 and PVR regulate monocyte migration through endothelial junctions. J Exp Med. 2004;199:1331-41.

40. Lenac Rovis T, Kucan Brlic P, Kaynan N, Juranic Lisnic V, Brizic I, Jordan $\mathrm{S}$, et al. Inflammatory monocytes and NK cells play a crucial role in DNAM-1-dependent control of cytomegalovirus infection. J Exp Med. 2016;213:1835-50.

41. Odegaard JI, Chawla A. Alternative macrophage activation and metabolism. Annu Rev Pathol. 2011;6:275-97.

42. Shan B, Wang X, Wu Y, Xu C, Xia Z, Dai J, et al. The metabolic ER stress sensor IRE1 1 alpha suppresses alternative activation of macrophages and impairs energy expenditure in obesity. Nat Immunol. 2017;18:519-29.

43. Boulenouar S, Michelet X, Duquette D, Alvarez D, Hogan AE, Dold C, et al. Adipose type one innate lymphoid cells regulate macrophage homeostasis through targeted cytotoxicity. Immunity. 2017;46:273-86.

44. Li P, Fan W, Xu J, Lu M, Yamamoto H, Auwerx J, et al. Adipocyte NCoR knockout decreases PPARgamma phosphorylation and enhances PPARgamma activity and insulin sensitivity. Cell. 2011;147:815-26.

45. Odegaard Jl, Ricardo-Gonzalez RR, Goforth MH, Morel CR, Subramanian V, Mukundan L, et al. Macrophage-specific PPARgamma controls alternative activation and improves insulin resistance. Nature. 2007;447:1116-20.

46. Pascual G, Fong AL, Ogawa S, Gamliel A, Li AC, Perissi V, et al. A SUMOylation-dependent pathway mediates transrepression of inflammatory response genes by PPAR-gamma. Nature. 2005;437:759-63.

47. Ricote M, Li AC, Willson TM, Kelly CJ, Glass CK. The peroxisome proliferator-activated receptor-gamma is a negative regulator of macrophage activation. Nature. 1998;391:79-82.

48. Charvet C, Canonigo AJ, Becart S, Maurer U, Miletic AV, Swat W, et al. Vav1 promotes T cell cycle progression by linking TCR/CD28 costimulation to FOXO1 and p27kip1 expression. J Immunol. 2006;177:5024-31.

49. Arden KC. FoxO: linking new signaling pathways. Mol Cell. 2004;14:416-8.

50. Kim DH, Lee B, Kim MJ, Park MH, An HJ, Lee EK, et al. Molecular mechanism of betaine on hepatic lipid metabolism: inhibition of forkhead box $\mathrm{O} 1$ (FoxO1) binding to peroxisome proliferator-activated receptor gamma (PPARgamma). J Agric Food Chem. 2016;64:6819-25.

51. Lehrke M, Millington SC, Lefterova M, Cumaranatunge RG, Szapary P, Wilensky R, et al. CXCL16 is a marker of inflammation, atherosclerosis, and acute coronary syndromes in humans. J Am Coll Cardiol. 2007:49:442-9.

52. Kielian T, Syed MM, Liu S, Phulwani NK, Phillips N, Wagoner G, et al. The synthetic peroxisome proliferator-activated receptor-gamma agonist ciglitazone attenuates neuroinflammation and accelerates encapsulation in bacterial brain abscesses. J Immunol. 2008;180:5004-16.

53. Lee KS, Kim SR, Park SJ, Park HS, Min KH, Jin SM, et al. Peroxisome proliferator activated receptor-gamma modulates reactive oxygen species generation and activation of nuclear factor-kappaB and hypoxia-inducible factor 1alpha in allergic airway disease of mice. J Allergy Clin Immunol. 2006;118:120-7.

54. Lee HT, Liu SP, Lin CH, Lee SW, Hsu CY, Sytwu HK, et al. A Crucial role of CXCL14 for promoting regulatory $T$ cells activation in stroke. Theranostics. 2017;7:855-75.

\section{Publisher's Note}

Springer Nature remains neutral with regard to jurisdictional claims in published maps and institutional affiliations. 